\title{
A Sustainable Financing Credit Rating Model for China's Small- and Medium-Sized Enterprises
}

\author{
Yu Cao ${ }^{1,2}$ and Shouyao Xiong ${ }^{1,3}$ \\ ${ }^{1}$ Business School, Central South University, Changsha, Hunan 410083, China \\ ${ }^{2}$ Department of Information Systems, School of Computing, National University of Singapore, Singapore 117418 \\ ${ }^{3}$ College of Mathematics and Computing Science, Changsha University of Science and Technology, Changsha, Hunan 410004, China
}

Correspondence should be addressed to Shouyao Xiong; xsymail_cscn@sina.com

Received 26 December 2013; Revised 20 February 2014; Accepted 23 February 2014; Published 31 March 2014

Academic Editor: Fenghua Wen

Copyright (C) 2014 Y. Cao and S. Xiong. This is an open access article distributed under the Creative Commons Attribution License, which permits unrestricted use, distribution, and reproduction in any medium, provided the original work is properly cited.

\begin{abstract}
This paper builds a sustainable financing credit rating index system for small- and medium-sized enterprises in China from the perspective of sustainability. Then, a quantitative model for credit rating evaluation based on our index system is proposed by using fuzzy analytic hierarchy process (FAHP), which has the advantage of considering both quantitative and qualitative factors. Our numerical example shows that the index system is effective and practical. Our system improves the existing credit rating system to a certain extent. The evaluation method proposed can play an important guiding role for China's small- and medium-sized enterprises in the current transformation age. In particular, interested stakeholders can use this model to evaluate the investment risk of companies, especially with a focus on sustainability.
\end{abstract}

\section{Introduction}

In the age of globalization, the energy issue has become the central topic in areas of international politics, economics and environmental protection, and so on and even becomes the focus of international politics. The infinite consumption of oil, coal, and so on results in a large number of greenhouse gas emissions, which destroys the balance of the carbon cycle and brings a fatal blow to the earth [1]. According to the report in Nature in 2012, China's carbon emissions rank in the first place and account for $28 \%$ of the total emission. Thus developing low-carbon economy is the trend of the economic development in China. Held on November 25, 2009, China's state council executive meeting made a decision that by 2020 China's unit of gross domestic product (GDP) $\mathrm{CO}_{2}$ emissions will be $40 \%$ to $45 \%$ lower than that in 2005 . In 2012, the Eighteenth National Congress of the CPC proposes to promote conservation culture for the first time. As it says, "promoting the green development, circulation development and low carbon development" is an unavoidable future direction. This is not only the sublimation of understanding the importance of protecting the environment; it also shows that to take the path of green development has become a firm strategic choice of China.

At present, China has more than 50 million smalland medium-sized enterprises, which create $60 \%$ of gross domestic product (GDP) and the import and export and provide $80 \%$ of urban jobs. As the mainstay of economic development, small- and medium-sized enterprises are faced with various challenges when promoting green development. Especially some emerging technology enterprises have made significant contributions to the economy. However, they often get a lower credit rating by using the existing credit rating system to evaluate credit. On one hand, it is because of their smaller proportion of fixed assets; on the other hand, it is due to the existing credit rating system itself. While executing credit rating index system of enterprises, commercial banks currently take a fancy to solvency and profitability in their choice of rating method, the rating index, and the index weight but pay little attention to the development and innovation ability of enterprises. As a result, these enterprises are in an awkward position in the government's financial policy guidance and practice, so they are badly in need of some comprehensive, objective financial 
tools to guide and support their development, which conform to China's economic transformation of the current. Credit rating is an important part of the credit origination and can be used for risk prevention and control. Therefore, it is very important to propose a more appropriate credit rating quantitative model for small- and medium-sized enterprises' financing and financial services at the present stage.

The credit rating process represents a subjective assessment of both quantitative and qualitative factors of a particular object [2]. In earlier researches, the linear method is given priority to the credit evaluation by scholars. Altman $[3,4]$ used multivariate analysis to predict the financial crisis, and by way of stepwise multivariate analysis method, he established the $Z$ value model and the ZETA model. Using Logit analysis in which the assumptions are relatively looser, Ohlson [5] established the prediction model and widened the sample difference between the experimental group and the control group for the first time, the results of which proved that the asset scale, capital structure, asset return rate, and short-term flows have statistical significance to evaluate the bankruptcy probability. Metz et al. [6] summarized the distribution of some common financial ratios of nonfinancial companies in North America and drew the following conclusions: fixed expenditure guarantee debt ratio, cash flow/sales revenue, profitability, sales stability, and average asset are all related to the strict monotone of credit grade, while the average return on assets and $Z$ values approximate but are not strictly monotone of credit grade. And the average liquidity ratios (cash and equivalents/total assets) are not associated with credit grade; no matter whether the credit rating is higher or lower, the corporate liquidity ratios are higher on average.

Linear methods tend to require that the research object be linear and accord with normal distribution, but it is quite different from the reality, which has characteristic of being nonlinear and nonnormal in both financial data and nonfinancial data. The evaluation method above cannot measure comprehensively the credit status and the actual risk of China's small- and medium-sized enterprises. At the same time, for small- and medium-sized enterprises in China, there is extremely a lack of the data for modeling. This paper, considering the practical situation of small- and mediumsized enterprises in China and according to the systematic, independent, scientific, operable, and objective principle, argues that in the pursuit of companies' development, it is necessary for them to satisfy a balanced development of the three aspects: economic prosperity, environmental protection, and social welfare. This is based on Triple Bottom Line (TBL) theory for the sustainable development of enterprises put forward by Elkington [7] in 1998, the President of Sustain Ability in Britain.

Motivated by the above, this paper classifies and reconstructs the credit rating index system in the perspective of sustainable development. Furthermore, based on the new sustainable credit rating index system, we establish a credit rating quantitative model for evaluating small- and mediumsized enterprises by fuzzy analytic hierarchy process, which has the advantage of combining both quantitative and qualitative factors.

\section{Sustainable Financing Credit Rating Index System for Small- and Medium-Sized Enterprise}

Considering the sustainable financing credit rating index classification principles and the process of simplified evaluation for small- and medium-sized enterprises, this paper obtains the entire credit rating index value, by evaluating the indicators one by one reversely from the bottom to upper level, synthesizing step by step, calculating index evaluation value for each layer. From the perspective of sustainability, the system of credit rating index systems is divided into three categories: economic benefit index, social benefit index, and environmental benefit index. (1) The economic benefit is one of the important indicators to measure the enterprise's financial risk, which many scholars have given great attention to [8-11]; it is also an important index of enterprise credit rating. According to the related literature $[5,6]$, we choose 9 evaluation indexes from production and business operation ability, profit ability, and innovation ability to apply; (2) Attig et al. [12] suggest that corporate social responsibility performance conveys important nonfinancial information. Social benefits are to make a contribution to the society and get some noneconomic returns. The international community generally believed that new responsibilities in the society should give enterprise connotation and value pursuit. Based on the stakeholder theory and [13], we establish five categories and set up 18 indexes for social benefits of smalland medium-sized enterprises; (3) environmental issues outstanding makes it necessary for enterprises to improve the efficiency of their environmental management. Therefore, according to the requirements of the scientific outlook on development, we set up six environmental indicators. The specific settings for index system are shown in Table 1.

\section{A Quantitative Model for Credit Rating}

3.1. The Credit Rating Index Hierarchy. With $P$ representing credit rating, with reference to the existing evaluation criteria for credit rating indexes, this paper divides $P$ into three classes and nine levels: AAA, AA, A, BBB, BB, B, CCC, $\mathrm{CC}$, and $\mathrm{C}$. After standardization the values range between 0 and 1, as shown in Table 2; this paper builds the mapping relationship between credit rating quantitative indicators and qualitative evaluation level.

\subsection{A Quantitative Model for Credit Rating Based on the} Sustainable Theory. This paper introduces the concept of membership degree by using fuzzy mathematics and makes the fuzzy evaluation of enterprises running state index quantitative; accordingly it constructs a fuzzy evaluation matrix for quantitative evaluation. Meanwhile, through the fuzzy analytic hierarchy process (AHP) to determine the fuzzy weights of indicators at the same level, adopting a bottomup sequence, this paper derives credit rating index value by using multilevel comprehensive evaluation method of reverse calculated comprehensive weighted evaluation; the basic process is as follows. 
TABLE 1: Credit rating index system.

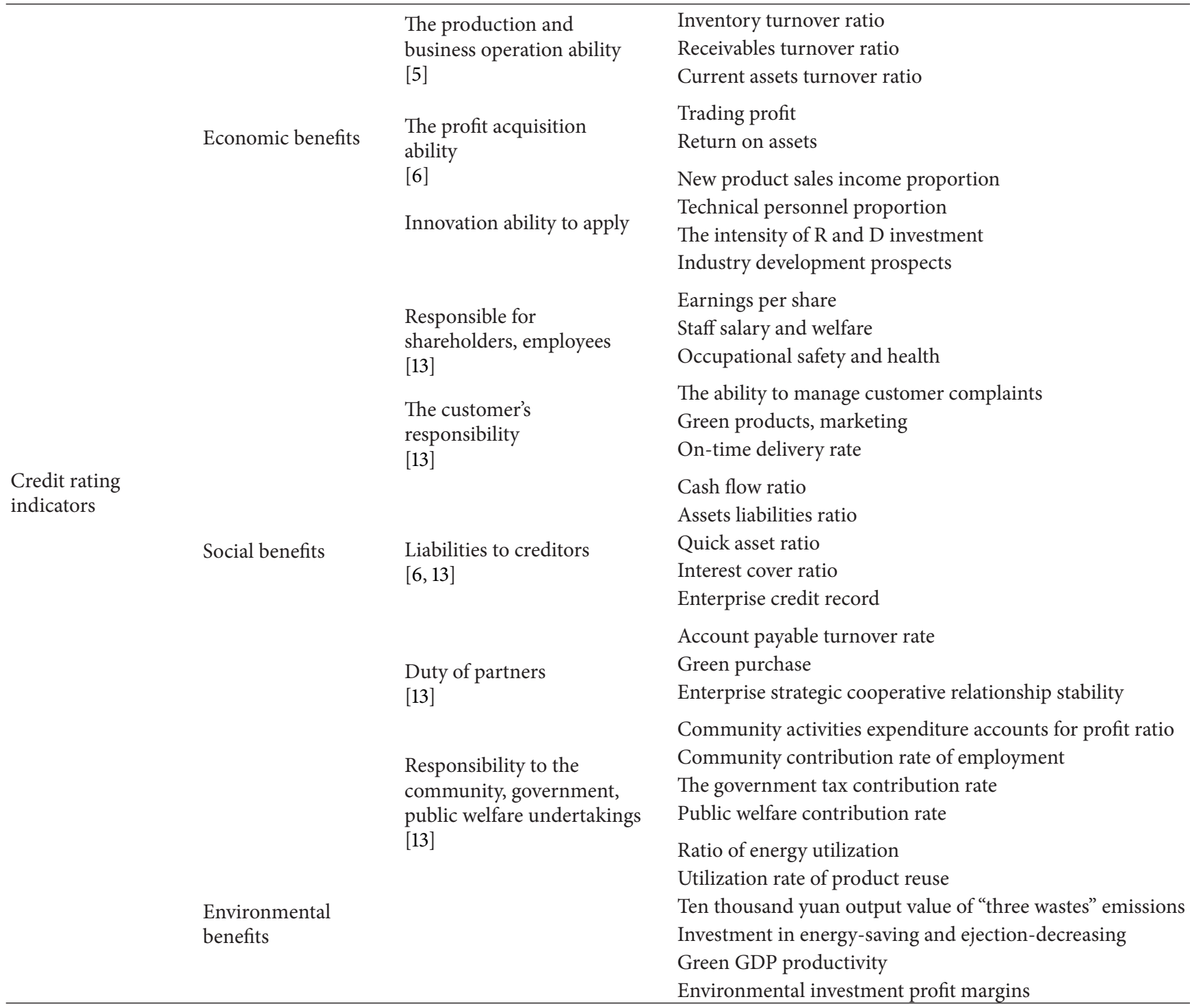

TABLE 2: Credit rating.

\begin{tabular}{lcc}
\hline Rank & $P$ value area & Credit ratings \\
\hline 1 & $0.9 \leq P \leq 1.0$ & AAA \\
2 & $0.8 \leq P<0.9$ & AA \\
3 & $0.7 \leq P<0.8$ & A \\
4 & $0.6 \leq P<0.7$ & BBB \\
5 & $0.5 \leq P<0.6$ & BB \\
6 & $0.4 \leq P<0.5$ & B \\
7 & $0 \leq P<0.4$ & CCC, CC, C \\
\hline
\end{tabular}

\subsubsection{The Determination of Weights}

(1) Judgment of Importance. Let $f(x, y)$ be the importance degree of $x$ and $y$ on the overall:

$$
f(y, x)=\frac{1}{f(x, y)} .
$$

Regarding $f(x, y)$, Saaty recommended list method [14], which is shown in Table 3.

(2) To Construct Judgment Matrix. Let $X=\left(x_{1}, x_{2}, \ldots, x_{n}\right)$ be the set of all factors; according to the meaning in Table 1, make comparison between every two factors of all it; get matrix $C=\left(c_{i j}\right) n \times n$.

(3) The Determination of Weight $a_{i}$. According to the judgment matrix $C$, calculate the maximum characteristic root $\lambda_{\text {max }}$ and the corresponding eigenvector $\varepsilon=\left(x_{1}, x_{2}, \ldots, x_{n}\right)$. To normalize the processing of $x$, get the weight set $A=$ $\left(a_{1}, a_{2}, \ldots, a_{n}\right)$.

(4) Check Consistency. Check consistency according to CR = $C_{i} / R_{i}$. Among them, $\mathrm{CR}$ is the random consistency ratio of the judgment matrix, and $C_{i}$ is the consistence index of judgment matrix, $C_{i}=\left(\lambda_{\max }-n\right) /(n-1) . R_{i}$ is the 
TABLE 3: Numbers 1-9 scale table.

\begin{tabular}{lcc}
\hline$x$ and $y$ qualitative comparison results & $f(x, y)$ & $f(y, x)$ \\
\hline$x$ and $y$ have the same importance & 1 & 1 \\
$x$ is a little more important than $y$ & 3 & $1 / 3$ \\
$x$ is obviously more important than $y$ & 5 & $1 / 5$ \\
$x$ is much more important than $y$ & 7 & $1 / 7$ \\
$x$ is extremely more important than $y$ & 9 & $1 / 9$ \\
$x$ to $y$ is between each level & $2,4,6,8$ & $1 / 2,1 / 4,1 / 6,1 / 8$ \\
\hline
\end{tabular}

TABLE 4: Modification value of consistency index $R_{i}$.

\begin{tabular}{lllllllllll}
\hline The matrix order1 & 2 & 3 & 4 & 5 & 6 & 7 & 8 & 9 & 10 & 11
\end{tabular}

\begin{tabular}{llllllllllll}
\hline$R_{i}$ & 0 & 0 & 0.58 & 0.96 & 1.12 & 1.24 & 1.32 & 1.41 & 1.45 & 1.49 & 1.52 \\
\hline
\end{tabular}

modification value of consistency index, which is shown in Table 4. If $\mathrm{CR}<0.1$, then judgment matrix has a satisfactory consistency and this weight distribution is reasonable. Otherwise, the judgment matrix needs to adjust until the satisfactory consistency is obtained.

3.2.2. A Quantitative Model for Credit Rating Based on the Sustainable Theory. Let $U=\left(u_{1}, u_{2}, \ldots, u_{n}\right)$ be " $n$ " kinds of factors of the evaluation objects, and let $V=\left(v_{1}, v_{2}, \ldots, v_{m}\right)$ be " $m$ " kinds of the judgment for the state of each factor. Here exist two kinds of fuzzy sets; one symbolizes the importance of each factor in factors set $U$ which manifests the fuzzy weighted vector $A=\left(a_{1}, a_{2}, \ldots, a_{n}\right)$. The other is a fuzzy relation, expressed as a fuzzy matrix $R_{n \times m}=U \times V$. These two fuzzy sets reflect people's values and preference structure. At present, the membership function comes out of a lot of statistical data and the analysis and conclusion of the expert's experience. According to credit rating index, this paper calculates the membership of $V_{1}(\mathrm{AAA}), V_{2}(\mathrm{AA}), V_{3}(\mathrm{~A}), V_{4}(\mathrm{BBB})$, $V_{5}(\mathrm{BB}), V_{6}(\mathrm{~B})$, and $V_{7}(\mathrm{CCC}, \mathrm{CC}, \mathrm{C})$ for each evaluation index in $U_{i}(i=1,2, \ldots, n)$, respectively, representing as

$$
\left(v_{1 i}, v_{2 i}, v_{3 i}, v_{4 i}, v_{5 i}, v_{6 i}, v_{7 i}\right)
$$

Compute $B=f(\mathrm{AR})$; then we can obtain a fuzzy subset $B=\left(b_{1}, b_{2}, \ldots, b_{n}\right)$ in $V$. Finally, according to $B=f(\mathrm{AR})$, we can conduct a comprehensive, objective, and integrated evaluation for the economic, social, and environmental benefits indexes of the credit rating indicators and the whole credit rating indexes.

\section{Empirical Research}

On the basis of the given index system of credit rating, this paper constructs a rating scale and conducts a credit rating for some emerging science and technology enterprises in Hunan. According to the evaluation results of ten evaluation experts, use Matlab software to analyze data processing, and the results of the analysis validate the validity and the practicability of the evaluation model.
TABle 5: The index weight under the $U_{3}$.

\begin{tabular}{ccccccc}
\hline$U_{3}$ & $U_{31}$ & $U_{32}$ & $U_{33}$ & $U_{34}$ & $U_{35}$ & $U_{36}$ \\
\hline$U_{31}$ & 1 & 1 & 5 & 7 & 6 & 3 \\
$U_{32}$ & 1 & 1 & 3 & 3 & 5 & 4 \\
$U_{33}$ & $1 / 3$ & $1 / 3$ & 1 & 4 & 4 & 3 \\
$U_{34}$ & $1 / 7$ & $1 / 3$ & $1 / 4$ & 1 & 4 & 2 \\
$U_{35}$ & $1 / 6$ & $1 / 5$ & $1 / 4$ & $1 / 4$ & 1 & 1 \\
$U_{36}$ & $1 / 3$ & $1 / 4$ & $1 / 3$ & $1 / 2$ & 1 & 1 \\
\hline
\end{tabular}

Take an example of one expert's evaluation results of the indexes under the environmental benefits; the weights are given in Table 5.

We get $\lambda_{\max }=6.61, C_{i}=0.122, R_{i}=1.24$ (by Table 4 ), and $\mathrm{CR}=C_{i} / R_{i}=0.098<0.1$. The consistency of judgment matrix is satisfactory and it shows that the weight allocation is reasonable. Calculate the weighted score of ten experts; we obtain the following result:

$$
A_{3}=\left[\begin{array}{llllll}
0.313 & 0.324 & 0.165 & 0.098 & 0.043 & 0.057
\end{array}\right] .
$$

According to the evaluation sheet, under the environmental benefit indexes of resources and energy utilization, green GDP contribution, energy conservation, and emissions reduction, the membership degree of the vector matrix is as follows:

$$
\begin{aligned}
R_{3}= & \left(\begin{array}{llllllll}
r_{1} & r_{2} & r_{3} & r_{4} & r_{5} & r_{6}
\end{array}\right)^{T} \\
& \left(\begin{array}{cccccccc}
0.1 & 0.3 & 0.5 & 0.1 & 0 & 0 & 0 \\
0.3 & 0.6 & 0.1 & 0 & 0 & 0 & 0 \\
0.5 & 0.4 & 0.1 & 0 & 0 & 0 & 0 \\
0.3 & 0.5 & 0.1 & 0.1 & 0 & 0 & 0 \\
0.2 & 0.4 & 0.4 & 0 & 0 & 0 & 0 \\
0.2 & 0.6 & 0.1 & 0.1 & 0 & 0 & 0
\end{array}\right) .
\end{aligned}
$$

Then,

$$
\begin{aligned}
\mathrm{EN}= & A_{3} R_{3} \\
& \left(\begin{array}{c}
0.313 \\
0.324 \\
0.165 \\
0.098 \\
0.043 \\
0.057
\end{array}\right)\left(\begin{array}{ccccccc}
0.1 & 0.3 & 0.5 & 0.1 & 0 & 0 & 0 \\
0.3 & 0.6 & 0.1 & 0 & 0 & 0 & 0 \\
0.5 & 0.4 & 0.1 & 0 & 0 & 0 & 0 \\
0.3 & 0.5 & 0.1 & 0.1 & 0 & 0 & 0 \\
0.2 & 0.4 & 0.4 & 0 & 0 & 0 & 0 \\
0.2 & 0.6 & 0.1 & 0.1 & 0 & 0 & 0
\end{array}\right) \\
= & {[5) } \\
\text { Let } & \left.V_{1}=0.260 .4550 .238, V_{2}=0.047 \quad 0 \quad 0 \quad 0\right] \\
V_{6}= & 0.45, \text { and } V_{7}=0.2 ; \text { then we have } \\
P_{3}= & 0.95 \times 0.26+0.85 \times 0.455+0.75 \times 0.238 \\
& +0.65 \times 0.047+0.55 \times 0+0.45 \times 0+0.2 \times 0 \\
= & 0.8428
\end{aligned}
$$

The same as above, we get $P_{1}=0.8293, P_{2}=0.80485$. According to the analytic hierarchy process, the index weight for the second layer relative to the first layer is

$$
A=\left[\begin{array}{lll}
0.594 & 0.249 & 0.157
\end{array}\right] \text {. }
$$


And then, we get the enterprise credit value

$$
\begin{aligned}
P & =0.594 \times 0.8428+0.249 \times 0.8239+0.157 \times 0.80485 \\
& \approx 0.87 .
\end{aligned}
$$

Therefore, we can conclude that the credit rating of the enterprise at that time is AA level and the evaluation result is basically in accord with the practical operation of the enterprise.

\section{Conclusion}

Credit rating for small- and medium-sized enterprises is quite complex because of many fuzzy factors involved. Based on the background of industrial economic transformation in China and the theory of sustainability and by using the fuzzy analytic hierarchy process, this paper constructs a set of practical credit rating index systems and a quantitative model for credit rating, which has certain practical significance.

Since the establishment of the credit rating index system has a strong correlation with actual situation, in view of the small- and medium-sized enterprises in different industries, further studies of the rating index and index weight are needed.

\section{Conflict of Interests}

The authors declare that there is no conflict of interests regarding the publication of this paper.

\section{Acknowledgments}

The authors would like to thank the anonymous referees for their useful comments and suggestions, which were very helpful in improving this paper. This paper is supported by the Major Project Fund of the National Science Foundation of Hunan (no. 12JJ2042) and the Innovative Research Group Science Fund of the National Science Foundation of China (no. 70921001).

\section{References}

[1] K.-H. Lee, "Integrating carbon footprint into supply chain management: The case of Hyundai Motor Company (HMC) in the automobile industry," Journal of Cleaner Production, vol. 19, no. 11, pp. 1216-1223, 2011.

[2] P. Hájek and V. Olej, "Credit rating modelling by kernel-based approaches with supervised and semi-supervised learning," Neural Computing and Applications, vol. 20, no. 6, pp. 761-773, 2011.

[3] E. I. Altman, "Financial ratios, discriminate analysis and the prediction of corporate bankruptcy," Journal of Finance, vol. 23, no. 4, pp. 76-79, 1968.

[4] E. I. Altman, R. G. Haldeman, and P. Narayanan, "ZETATM analysis A new model to identify bankruptcy risk of corporations," Journal of Banking and Finance, vol. 1, no. 1, pp. 29-54, 1977.

[5] J. A. Ohlson, "Financial ratios and the probabilistic prediction of bankruptcy," Journal of Accounting Research, no. 18, pp. 109131, 1980.
[6] A. Metz, R. Cantor, and P. Stump, "The effectiveness of credit rating as indicators of relative industry default risk," Moody's Investors Service, no. 2, pp. 74-81, 2004.

[7] J. Elkington, "Partnerships from cannibals with forks: the triple bottom line of 21st-century business," Environmental Quality Management, no. 1, pp. 37-51, 1998.

[8] F. Wen and Z. Liu, "A copula-based correlation measure and its application in chinese stock market," International Journal of Information Technology and Decision Making, vol. 8, no. 4, pp. 787-801, 2009.

[9] W. Fenghua, L. Zhong, X. Chaohua, and S. David, "Study on the fractal and chaotic features of the Shanghai composite index," Fractals-Complex Geometry Patterns and Scaling in Nature and Society, vol. 20, no. 2, pp. 133-140, 2012.

[10] C. Huang, C. Peng, X. Chen, and F. Wen, "Dynamics analysis of a class of delayed economic model," Abstract and Applied Analysis, vol. 2013, Article ID 962738, 12 pages, 2013.

[11] C. Huang, X. Gong, X. Chen, and F. Wen, "Measuring and forecasting volatility in Chinese stock market using HAR-CJ-M model," Abstract and Applied Analysis, vol. 2013, Article ID 143194, 13 pages, 2013.

[12] N. Attig, S. El Ghoul, O. Guedhami, and J. Suh, "Corporate social responsibility and credit ratings," Journal of Business Ethics, vol. 117, pp. 679-694, 2013.

[13] M. Sheng, K. Haibo, and Z. Xiaonan, “The corporate social responsibility evaluation model based on the concept of scientific development," Science Research Management, vol. 33, no. 3, pp. 148-154, 2012 (Chinese).

[14] G.-F. Bin, X.-J. Li, B.-S. Dhillon, and W.-W. Chu, "Quantitative system evaluation method for equipment state using fuzzy and analytic hierarchy process," System Engineering Theory and Practice, vol. 30, no. 4, pp. 744-750, 2010 (Chinese). 


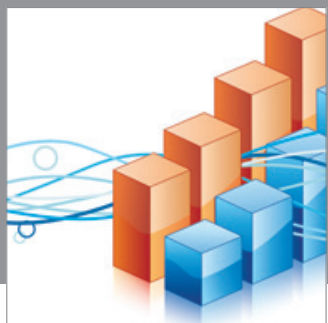

Advances in

Operations Research

mansans

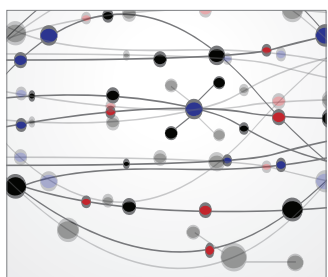

The Scientific World Journal
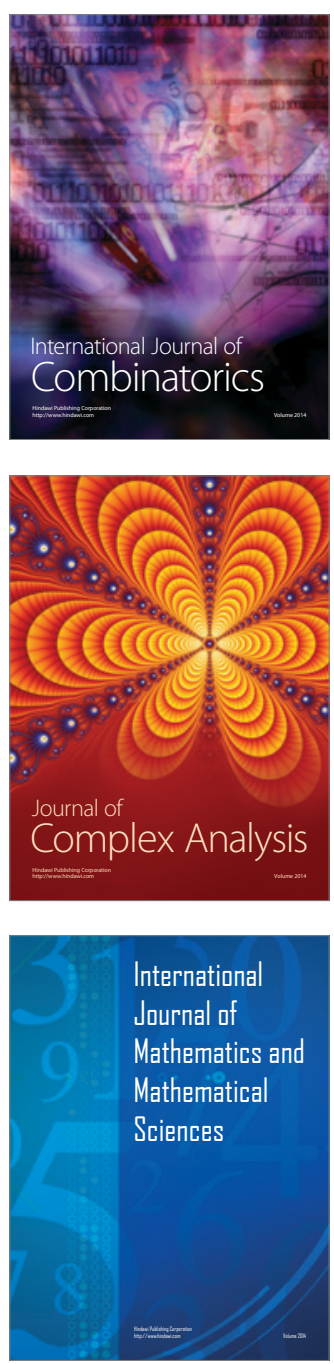
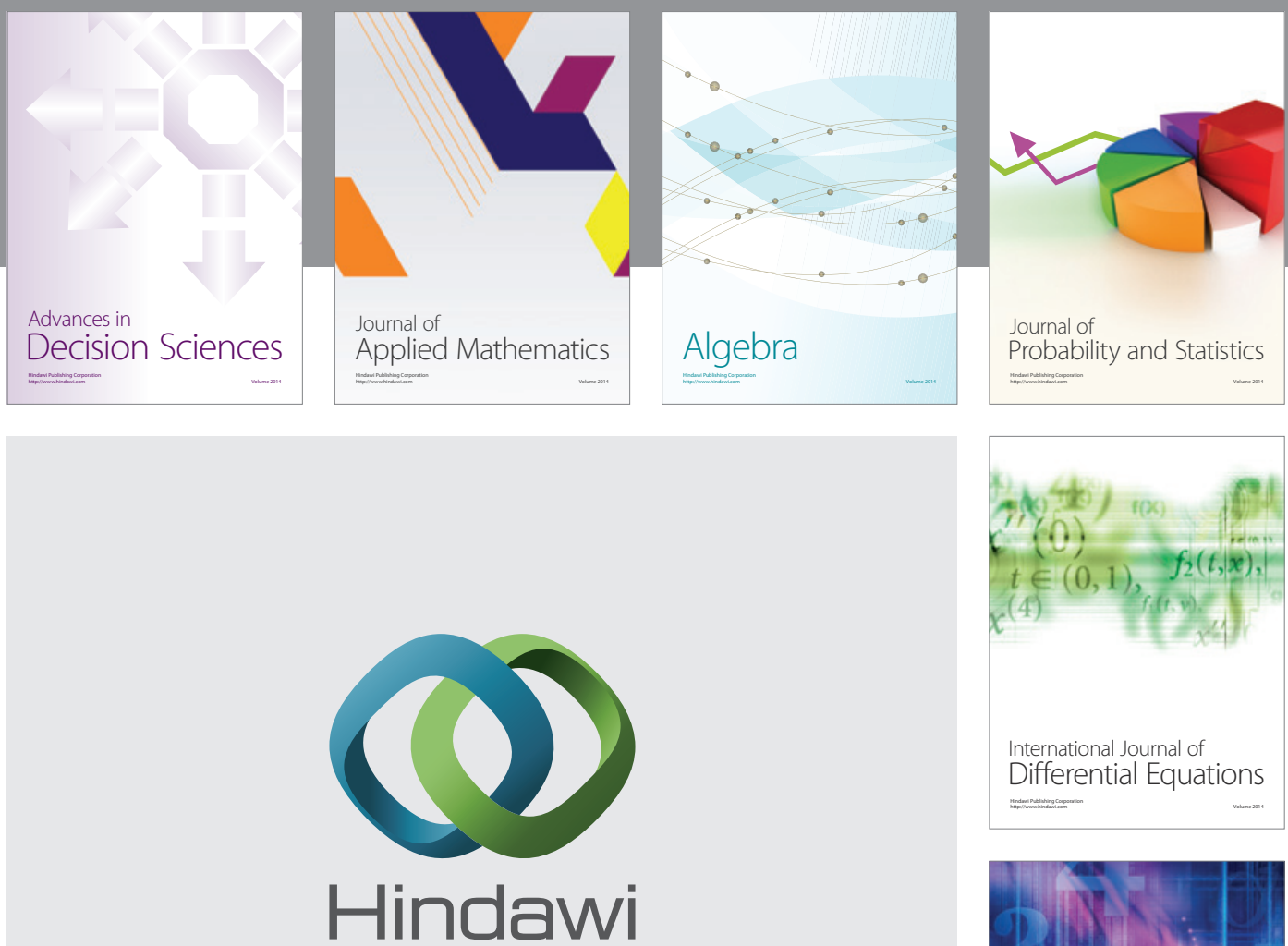

Submit your manuscripts at http://www.hindawi.com
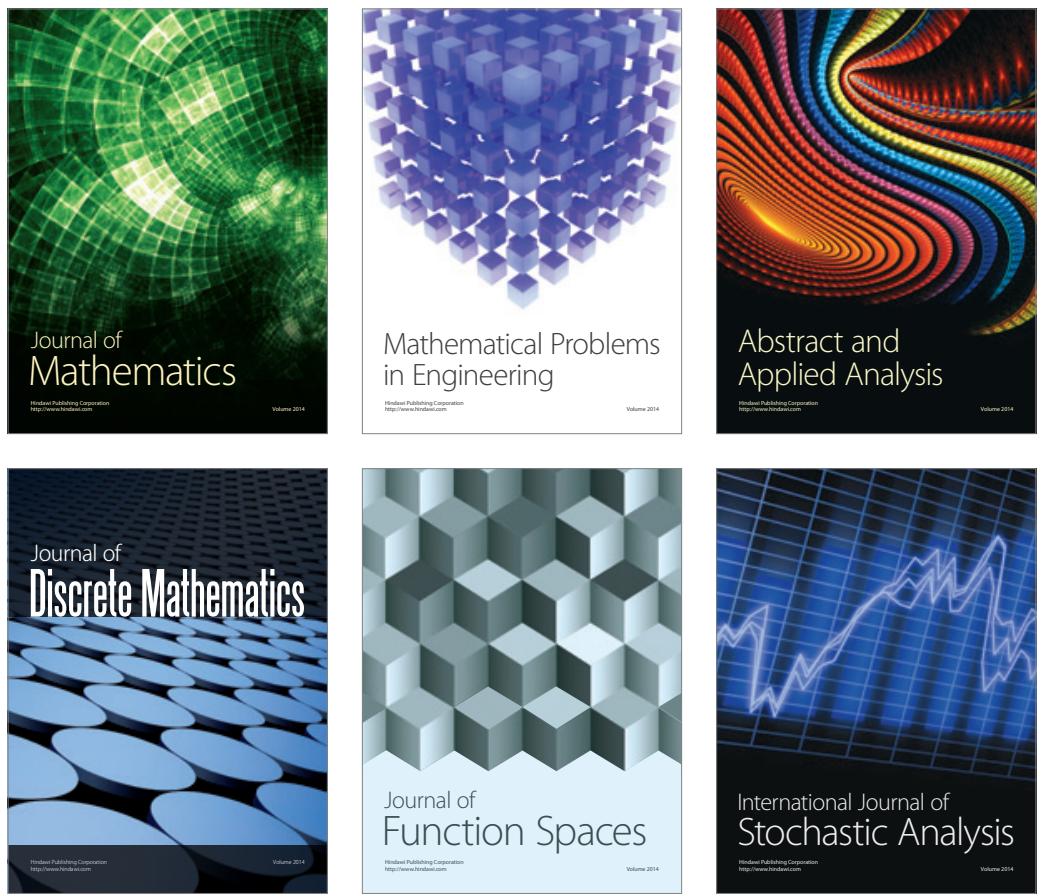

Journal of

Function Spaces

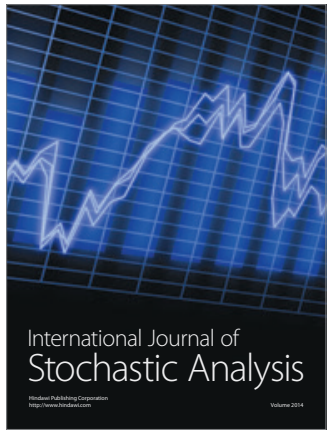

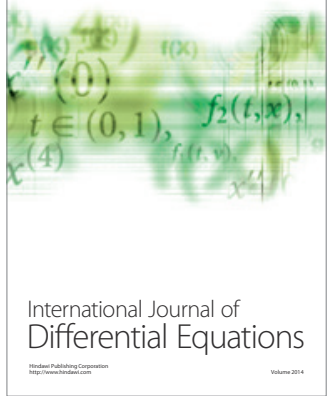
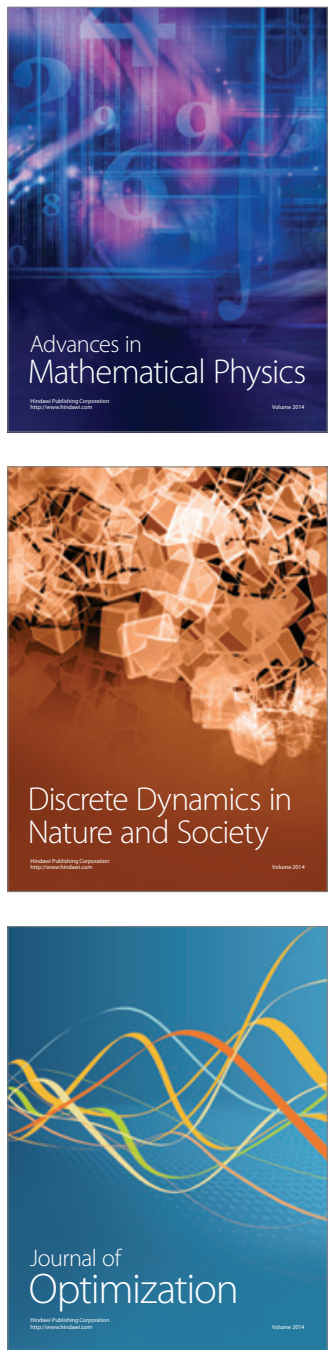